\title{
PENGEMBANGAN MEDIA AUDIO VISUAL SEBAGAI UPAYA PENINGKATAN MINAT BELAJAR SISTEM KOPLING DI UNIVERSITAS MUHHAMADIYAH PURWOREJO
}

\author{
Oleh : Ryan Yusuf, Aci Primartadi Pendidikan Teknik Otomotif Fakultas Keguruan \\ dan Ilmu Pendidikan Universitas Muhammadiyah Purworejo. \\ E-mail : yusufryan22@gmail.com, Aci@umpwr.ac.id
}

\section{ABSTRAK}

Penelitian ini bertujuan untuk 1) Mengetahui prosedur pengembangan media pembeajaran berbasis audio visual sistem kopling.2) Untuk mengetahui minat belajar mahasiswa pendidikan teknikotomotif semester 4 di Universitas Muhammadiyah Purworejo.3) Mempermudah pemahaman mahasiswa non SMK terhadap materi sistem pemindah tenaga khususnya pada pelajaran sistem kopling semester 4 di Universitas Muhammadiyah Purworejo.4) Meningkatkan minat belajar mahasiswa terhadap materi system pemindah tenaga khususnya pada pelajaran system kopling semester 4 Universitas Muhammadiyah Purworejo.

Penelitian ini menggunakan metode Reseach and Development (R \& D) dengan subyek penelitian yang diambil adalah mahasiswa semester 4 kelas $B$ Pendidikan Teknik Otomotif Universitas Muhammadiyah Purworejo yang bejumlah 39 mahasiswa. Pengumpulan data menggunakan metode kuesioner (angket) untuk mengetahui kelayakan media yang digunakan menggunakan lembar tanggapan mahasiswa dan angket minat belajar mahasiwa menggunakan angket minat belajar mahasiswa.

Dari hasil penelitian, menunjukan bahwa : 1) prosedur pengembangan media pembelajaran sistem audio visual sistem kopling meliputi pencarian potensi masalah, pengumpulan data, desain produk, validasi desain, perbaikan desain, uji coba produk, pengujian produk, uji coba pemakaian dan revisi produk. 2) media pembelajaran system audio visual sistem kopling layak digunakan untuk media pembelajaran. Hal ini dapat dibuktikan dari ahli media yang menunjukan skor rata - rata 3,1. Validasi dari ahli materi yang menunjukan skor rata - rata 3,4. Media pembelajaran sistem audio visual system kopling juga telah memenuhi kriteria kualitas media pembelajaran. Hal ini ditunjukkan melalui respon mahasiswa yaitu meliputi uji coba kelompok kecil memperoleh skor rata - rata 3,43 yang meliputi 5 mahasiswa dan uji coba kelompok besar memperoleh skor rata - rata 3,13. 3) Pada minat belajar mahasiswa menunjukan bahwa media pembelajaran audio visual sistem kopling dapat meningkatkan minat belajar mahasiswa semester 4 kelas B di Universitas Muhammadiyah Purworejo.

Kata Kunci : Media Pembelajaran, Audio Visual Sistem Kopling, Minat Belajar 


\section{PENDAHULUAN}

Kata media berasal dari bahasa latin medius yang secara harfiah berarti 'tengah', 'perantara' atau 'pengantar'. Azhar Arsyad, (2017:3) mengemukakan media, dalam bahasa arab, media adalah perantara atau pengantar pesan dari pengirim kepada penerima pesan. Daryanto dalam Umam (2017:19) kata media merupakan bentuk jamak dari kata medium. Heinich dan kawan-kawan yang dikutip oleh Azhar Arsyad (2017:3) mengemukakan istilah medium dapat didefinisikan sebagai perantara atau pengantar terjadinya komunikasi dari pengirim menuju penerima. Media merupakan suatu komponen komunikasi yaitu sebagai pembawa pesan dari komunikator menuju komunikan (Criticos dalam Umam 2017:19).

Media berasal dari kata latin adalah bentuk jamak dari medium batasan dari pengertian media sangat luas, namun kita batasi pada media pendidikan saja yakni media yang digunakan sebagai alat dan bahan kegiatan pembelajaran. Istilah "media" bahkan sering dikaitkan atau dipergantikan dengan kata "teknologi" yang berasal dari kata latin tekne (bahasa Inggris art) dan logos (bahasa Indonesia "ilmu"). Hal tersebut didukung oleh Webster dalam Azhar Arsyad (2017:5), "art" adalah keterampilan (skill) yang diperoleh lewat pengalaman, studi dan observasi. Dengan demikian, teknologi tidak lebih dari satu ilmu yang membahas tentang keterampilan yang diperoleh lewat pengalaman, studi, dan observasi. Secara lebih khusus, pengertian media dalam proses belajar mengajar cenderung diartikan sebagai alat-alat grafis, fotologis, atau elektronis untuk menangkap, memproses, dan menyusun kembali informasi visual atau verbal.

Media pembelajaran digunakan untuk meningkatkan kegiatan proses belajar mengajar. Mengingat banyaknya bentuk-bentuk media tersebut, maka guru harus dapat memilihnya dengan cermat, sehingga dapat digunakan dengan tepat. Dalam kegiatan belajar mengajar, sering pula pemakaian kata media 
pembelajaran digantikan dengan istilah-istilah seperti: bahan pembelajaran (instructional material), komunikasi pandang-dengar (audio-visual communication), alat peraga pandang (visual education), alat peraga dan media penjelas.

Dengan adanya media pembelajaran audio visual diharapkan minat belajar mahasiswa Pendidikan Teknik Otomotif Universitas Muhammadiyah Purworejo meningkat

\section{METODE PENELITIAN}

Jenis penelitian yang digunakan adalah penelitian dan pengembangan atau Research and Development, dengan 10 langkah prosedur pengembangan. Penelitian ini dilaksanakan di Universitas Muhammadiyah Purworejo yang beralamat jl. K.H.A Dahlan 3 Purworejo. Waktu pelaksanaan penelitian ini pada bulan September 2019 sampai selesai. Subjek dalam penelitian ini adalah mahasiswa semester 4 kelas B Pendidikan Teknik Otomotif Universitas Muhammadiyah Purworejo tahun ajaran 2018/2019 yang berjumlah 39 mahasiswa yang mendapatkan materi Sistem kopling di mata kuliah sistem pemindah tenaga . Data yang digunakan dalam penelitian ini diperoleh melalui metode kuesioner (angket).

Instrumen yang digunakan pada penelitian ini meliputi instrument tanggapan ahli media, tanggapan ahli materi, tanggapan mahasiswa. Instrumen pengumpulan data yaitu menggunakan kuesioner (angket). Jenis data penelitian ini adalah menggunakan angket minat belajar mahasiswa dan lembar tanggapan mahasiswa.

\section{HASIL PENELITIAN DAN PEMBAHASAN}

Penelitian ini menunjukan adanya perbedaan pengaruh media pembelajaran audio visual sistem kopling terhadap peningkatan minat belajar Jurnal Pendidikan Teknik Otomotif_Universitas Muhammadiyah Purworejo 
pada mahasiswa kelas B semester 4 pendidikan teknik otomotif Universitas Muhammadiyah Purworejo tahun ajaran 2018-2019.

Minat belajar mahasiswa semester 4 kelas $B$

\begin{tabular}{|l|l|}
\hline \multicolumn{1}{|c|}{ Indikator Statistik } & \multicolumn{1}{c|}{ Nilai } \\
\hline Rata-rata & 85.84 \\
\hline Skor Tertinggi & 96 \\
\hline Skor Terendah & 79 \\
\hline Modus & 86 \\
\hline Median & 86 \\
\hline Standar Deviasi & 3.2244 \\
\hline
\end{tabular}

Lembar tanggapan mahasiwa

\begin{tabular}{|l|c|}
\hline Indikator Statistik & Nilai \\
\hline Rata-rata & 33.12 \\
\hline Skor Tertinggi & 36.00 \\
\hline Skor Terendah & 28.00 \\
\hline Median & 33.00 \\
\hline Modus & 32.00 \\
\hline Standar Deviasi & 2.2615 \\
\hline
\end{tabular}

Tabel Hasil minat belajar mahasiswa mendapatkan hasil penelitian yang di mana nilai atau skor rata - rata minat belajar mahasiswa yang di dapatkan dari angket minat belajar mahasiswa di peroleh dengan nilai rata - rata 85.84.

Lembar tanggapan mahasiswa untuk menghitung seberapa minat mahasiswa terhadap media audio visual sistem kopling mendapatka data bahwa rata - rata mahasiswa semester 4 kelas B Pendidikan Teknik Otomotif Universitas Muhammadiyah Purworejo tertarik dengan media audio visual yang saya terapkan dengan rata - rata tanggapan mencapai skor 33.12 dari maksimal skor 60.00 dan dapat di kategorikan baik.

\section{SIMPULAN DAN SARAN}


Dari hasil penelitian dan pengembangan ini, maka dapat disimpulkan adalah sebagai berikut :

1. Tahap pengembangan media pembelajaran sistem pengapian pada mahasiswa semester 4 kelas B Pendidikan Teknik Otomotif Universitas Muhammadiyah Purworejo telah meliputi pencarian potensi masalah, pengumpulan data, desain produk, validasi desain, perbaikan desain, uji coba produk, pengujian produk, uji coba pemakaian dan revisi produk.

2. Hasil validasi produk oleh ahli materi 3,4 (sangat baik), ahli media 3,1 (baik), uji coba kelompok kecil 3.43 (baik), dan uji coba pemakaian produk 3,43 (sangat baik). Dari hasil penilaian tersebut menunjukkan produk layak (baik) digunakan sebagai media pembelajaran.

3. Hasil penelitian mencangkup lembar tanggapan mahasiswa yang mendapatkan nilai rata - rata 33.12 ( baik) dan rata - rata angket minat belajar mahasiswa mendapatkan nilai 85.84 ( baik)

Agar produk yang dihasilkan bisa dimanfaatkan secara maksimal dalam kegiatan pembelajaran, maka ada beberapa saran yang terkait dengan media pembelajaran audio visual system kopling antara lain :

\section{Bagi Perguruan Tinggi}

Lembaga hendaknya menerapkan media pembelajaran di semua mata kuliah. Serta melengkapi sarana dan prasarana yang dibutuhkan untuk menunjang media pembelajaran tersebut.

2. Bagi Mahasiswa 
Melalui penelitian ini diharapkan media pembelajaran audio visual system kopling diharapkan mahaiswa dapat mengalami peningkatan minat belajar mahasiswa.

\section{DAFTAR PUSTAKA}

Arsyad, Azhar. 2017. Media Pembelajaran. Jakarta: PT. Raja Grafindo Persada.

Sugiyono. 2015. Metode Penelitian Pendidikan. Bandung: Alfabeta. 